cetiva se esta for diagnosticada quando estamos perante dentição mista. No que diz respeito à etiologia, a erupção palatina dos incisivos superiores, história de traumatismo nos incisivos decíduos e a presença de dentes supranumerários são algumas das situações que poderão dar origem a este tipo de mordida. Neste sentido, devemos intervir o mais precocemente possível, impedindo que esta anomalia permaneça e se consolide de forma esquelética.

Descrição do caso clínico: Paciente do sexo masculino, saudável, com 10 anos de idade, apresentou-se na Clínica Universitária da UCP. Após exame intra-oral, diagnosticou-se mordida cruzada anterior e posterior com classe I molar. A sua higiene oral era razoável. Por apresentar um dente cruzado (2.1), o motivo da consulta centrou-se no descontentamento face ao seu sorriso. Em concordância com os pais e a criança, decidiu-se proceder à realização de uma rampa em compómero (Twinky Star da Voco). O compómero foi o material de eleição, uma vez que permite escolher a cor deste mesmo, facilitando, posteriormente, a sua remoção. Deste modo, a rampa foi estabelecida no dente 3.1 com uma inclinação de 450 , de forma a que o dente 2.1 ocluísse na rampa e existisse uma desoclusão posterior.

Discussão e conclusões: Neste caso clínico, foram realizadas duas consultas de controlo. Na 1. ${ }^{\text {a }}$ consulta, após uma semana, o dente já se apresentava descruzado, indicando o sucesso do procedimento executado. A segunda consulta de controlo foi realizada 3 semanas depois do início do tratamento. Sempre com vista a um melhor resultado estético e funcional decidiu-se permanecer com a rampa por mais umas semanas. O paciente estava visivelmente satisfeito com a aparência do seu sorriso. A rampa foi removida 6 semanas depois, período de tempo em que se considerou existir estabilidade do dente 2.1 na sua posição. Concluiu-se que a opção de tratamento eleita foi eficaz, segura, rápida e económica. O paciente notou uma melhoria significativa no seu sorriso, ficando feliz com o resultado obtido.

http://doi.org/10.24873/j.rpemd.2017.12.085

\section{\#058 Anquilose de molares decíduos: diagnóstico e tratamento}

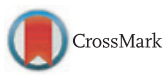

Ana Roseiro, Luisa Maló*, Inês Alexandre Neves Francisco, Francisco Fernandes do Vale

Faculdade de Medicina da Universidade de Coimbra

Introdução: A anquilose dentária resulta da fusão do osso alveolar ao cemento. É uma anomalia de erupção, frequente na dentição decídua, sendo reconhecida como um dos fatores etiológicos da infra-oclusão. A sua etiologia não é totalmente conhecida, mas a predisposição genética, pressão mastigatória excessiva e distúrbios no metabolismo local poderão ser fatores implicados. Os dentes decíduos são geralmente mais afetados do que os definitivos (ratio 10:1), sendo os molares inferiores de leite, os dentes com maior probabilidade de anquilose.

Descrição do caso clínico: Paciente do sexo feminino com 12 anos de idade, saudável, veio à consulta com dente 85 anquilosado. No exame intra-oral o dente não era visível (anqui- lose grave), existia tipping mesial do dente 46, extrusão do dente 55 e ausência de espaço para a erupção do dente 45 . No exame radiográfico confirmou-se o diagnóstico. Atendendo à idade da paciente e à cronologia da erupção dentária, o plano de tratamento realizado foi: exodontia do dente 85 e colocação de aparelho fixo multibrackets bimaxilar de modo a recuperar o espaço perdido e a normalizar a oclusão.

Discussão e conclusões: A infra-oclusão de molares decíduos está muitas vezes relacionada com um quadro subjacente de anquilose dentária. O seu diagnóstico é realizado com base no exame intra-oral onde se poderá verificar: a diminuição local do plano oclusal e um som surdo à percussão vertical, e sinais radiográficos como a ausência parcial ou total do ligamento periodontal. Em casos mais graves os dentes poderão estar numa posição infragengival. O tratamento deverá ser ajustado às alterações presentes, sendo o diagnóstico precoce a chave para um prognóstico favorável uma vez que a anquilose dentária apresenta um carácter progressivo. Quando tardiamente diagnosticada poderá ocorrer o desenvolvimento de sequelas cujo tratamento tende a ser longo, complexo e oneroso.

http://doi.org/10.24873/j.rpemd.2017.12.086

\section{\#059 Classe III - fase 1, fase 2 e pós-contenção - Caso clínico.}

Saúl Castro, Cristina Areias*, Ana Norton, Eugénio Martins, Paula Macedo, Maria Pollmann

\section{FMDUP}

Introdução: Nos casos de má-oclusão Classe III pode observar-se retromaxila, promandibulia ou uma combinação destes sinais, e, muitas vezes associada a uma atresia maxilar que geralmente se manifesta por mordidas cruzadas anteriores, posteriores, uni ou bilaterais. O relato deste caso clínico tem como objetivo avaliar os efeitos no perfil facial e na oclusão da terapia ortodôntica intercetiva (fase 1). O tratamento realizado com expansão e avanço maxilar foi executado na fase de crescimento para que atuasse no sistema sutural e o efeito ortopédico fosse efetivo. A colaboração do paciente é importante para o sucesso do tratamento, o tempo de uso da máscara na é primordial para que os efeitos faciais e oclusais se verifiquem. O desafio na fase de aparelho fixo bimaxilar (fase 2) foi o controlo da estabilidade oclusal, atendendo às múltiplas agenesias existentes $(15,35,45,37,47)$. No final do tratamento ortodôntico, a idade da doente ainda não permite uma reabilitação protética adequada, assim ao controlo (pós-contenção) para a futura reabilitação protética associa-se a necessidade de acompanhamento dos pacientes com má oclusão de Classe III até o final do crescimento.

Descrição do caso clínico: Paciente do sexo feminino com 8 anos de idade, braquifacial, padrão esquelético de Classe III, perfil côncavo e retrusivo. Retromaxila e promandibulia com retro-inclinação incisiva mandibular. Compressão maxilar, apinhamento na arcada maxilar de $11 \mathrm{~mm}$ e agenesia de dentes $15,35,45,37$ e 47 . Sobremordida horizontal de $-1 \mathrm{~mm}$ e vertical de $1,5 \mathrm{~mm}$. 